\title{
As "Batalhas do Rio": as metáforas de guerra e as políticas para as favelas cariocas (1946-1961)
}

\section{Samuel Silva Rodrigues de Oliveira* (1)}

\section{Resumo}

O artigo analisa a política das favelas e observa a permanência da retórica das "batalhas das favelas" em discursos de diferentes agentes sociais que reproduziam os parâmetros de uma cidadania escassa e limitada. As metáforas da guerra legitimaram os projetos de intervenção na cidade do Rio de Janeiro que tinham como perspectiva a diferenciação entre "trabalhadores favelados" e "classes perigosas" no acesso a políticas de assistência e aos direitos sociais, que enfatizavam a proposição de uma pedagogia cívica para recuperação da "urbanidade" dos moradores, e que articulavam uma representação heterotópica da informalidade urbana das favelas. A análise parte de uma pesquisa documental ampla em relatórios oficiais, legislações e na imprensa, analisando a forma como a metáfora da guerra articulava-se às arenas de conflito na cultura política carioca.

Palavras-chave: favelas, Rio de Janeiro, políticas urbanas, cultura política, história urbana.

\footnotetext{
* Centro Federal de Educação Tecnológica Celso Suckow da Fonseca, Rio de Janeiro, RJ, Brasil.
} 


\section{The "Battles of Rio": war metaphors and policies for Rio's favelas (1946-1961)}

\section{Abstract}

The article analyzes the politics surrounding the favelas (shantytowns) of Rio de Janeiro, Brazil, and observes the permanence of the rhetoric of the "battles of the favelas" in the discourses of different social agents, which reproduced the ideas of a limited citizenship. The metaphors of war helped to legitimate urban projects in the city of Rio de Janeiro, which planned to distinguish "favelado workers" from "dangerous classes" in accessing welfare policies and social rights, proposed a civic pedagogy to recover the "urbanity" of the residents in favelas, and articulated a heterotopic representation of the urban informality in Rio de Janeiro. The analysis is based on extensive documentary research in official reports, legislation and in the press, analyzing how the metaphor of war was linked to the arenas of conflict in Rio's political culture.

Keywords: favelas, Rio de Janeiro, urban policies, political culture, urban history.

campanha jornalística intitulada "Batalha do Rio" foi liderada por
Carlos Lacerda, entre os meses de maio e julho de 1948, no jornal
Correio da Manhã, e ganhou repercussão em vários outros periódicos do país. O jornalista foi um dos políticos mais populares do Rio de Janeiro e usava a imagem das favelas para conclamar uma ação cívica de diferentes atores sociais. Ao mobilizar a opinião pública, a "batalha das favelas" tornouse uma figura retórica na imprensa carioca, sendo uma referência mesmo quando os projetos diferiam daquilo que foi elaborado ou discutido pelo político udenista. A campanha de Lacerda teve tal repercussão nos órgãos de imprensa e fixação no imaginário social que, em 1955, o jornalista Edmar Morel escreveu uma série de reportagens sobre os descaminhos das várias "soluções" encontradas para o "problema da favela" e intitulou a série de reportagens da seguinte maneira: "A história secreta da batalha das favelas". ${ }^{1}$

1 Para a leitura do conjunto de reportagens de Edmar Morel, veja o mês de novembro de 1955 do jornal Última Hora. 
A campanha jornalística da "Batalha do Rio" criou um tropo retórico na opinião pública, que foi recuperado ao longo da década de 1950, para legitimar os diferentes projetos de intervenção nas favelas e na modernização do espaço urbano. Essa categoria retórica pode ser lida como um traço da cultura política carioca, ${ }^{2}$ compreendida como "uma rede de referências muitas vezes ambíguas, paradoxais e ambivalentes - que corresponderia à complexa estruturação de seu campo político" (Motta et al., 2004, p. 51). Em torno das "batalhas das favelas", organizaram-se os projetos de intervenções urbanísticas e as articulações políticas que singularizaram a história política do Rio de Janeiro, definiram um campo de disputa entre atores e governos distintos e estabeleceram uma forma de cidadania escassa para os moradores em favelas.

Ao analisar o período da experiência de democracia após o Estado Novo, a sociologia urbana e a história social enfatizam alguns traços que estruturaram as políticas das favelas. Primeiro, elas estabeleceram-se a partir de uma retórica da "marginalidade social" que ora identificava os moradores como "operários" e "trabalhadores do Brasil", sendo portadores de direitos, ora como um "rurícola" inadaptado aos hábitos urbanos, em parte "classes perigosas", devendo ser reprimidos, educados ou enviados de volta ao "interior". Segundo, as políticas da cidade enquadraram a informalidade urbana das favelas como "ilegal", propondo intervenções sociais e urbanísticas de "desfavelamento", que tinham como perspectiva a remoção ou "erradicação" das favelas e o desenvolvimento de pedagogias civilizatórias para os moradores. Terceiro, as políticas urbanas tinham como

\footnotetext{
${ }^{2}$ A noção de cultura política carioca foi desenvolvida nos trabalhos de Marieta de Moraes Ferreira, Marly Motta, Américo Freire e Carlos Eduardo Sarmento para a compreensão da história social e política do Rio de Janeiro. Segundo os autores, a cidade e o estado do Rio de Janeiro constituem um campo com agentes sociais e políticos heterogêneos, com recursos econômicos e simbólicos desiguais, e marcado pela capitalidade da região que foi sede da corte no governo imperial, capital federal e que enfrentou os embates da separação e "fusão" do estado da Guanabara e Rio de Janeiro. A noção de cultura política carioca problematiza a trajetória da política fluminense e carioca que constantemente é capturada pela memória social de uma "Era de Ouro" da cidade e do estado, e pela imagem do Rio de Janeiro como "espelho da nacionalidade", desconsiderando a heterogeneidade das posições e as agências sociais e políticas. Cf. Ferreira (2000) e Motta et al. (2004).
} 
perspectiva a construção de uma representação da favela encapsulada na reprodução dos estigmas de classe e raça em discursos heterotópicos, formados a partir de imagens e pressupostos do que seria uma cidade ideal e normal, sendo as favelas vistas como um "problema" e um lugar da "desordem" (Parisse, 1969; Leeds; Leeds, 1978; Valla, 1986; Machado da Silva, 2002; Campos, 2005; Valladares, 2005; Silva, 2005; Burgos, 2006; Fischer, 2004; 2008; Leite, 2012; Gonçalves, 2013; Oliveira, 2014).

Nem sempre as análises da sociologia urbana e da história social conseguiram mostrar a forma como o tropos retórico e metafórico das "batalhas" se impôs como parte da cultura política carioca e foi estruturante dos discursos e práticas sociais que tinham como pressuposto os limites para o reconhecimento da cidadania dos trabalhadores e moradores em favelas. Ao assumir esse enfoque, o artigo propõe um diálogo com os trabalhos de Márcia Pereira Leite e Antônio Luís Machado da Silva. Na conjuntura da democracia e do neoliberalismo nas décadas de 1990 e 2000, os dois pesquisadores evidenciaram como a metáfora da guerra se atualizou nas imagens da "cidade partida" e na sociabilidade violenta, para o controle dos territórios da informalidade urbana, construindo uma cidadania escassa nas abordagens do poder público, da imprensa e de outros agentes sociais em relação às favelas cariocas (Leite, 2000; 2012; Machado da Silva, 2008). Este artigo mostra como o tropo da guerra inscreve-se na longa duração da formação do campo político carioca, e assume significados específicos na democracia liberal do pós-guerra como será demonstrado nas três subseções de nossa análise. Um traço de permanência nas diferentes configurações sociais analisadas, e na atualidade, é a interdição do direito dos moradores de aparecer e reivindicar direitos como um dos pressupostos do discurso que enquadra o "problema" das favelas na retórica da "batalha" ou "guerra".

Ao compreender as dinâmicas da política das favelas a partir da retórica das "batalhas", o artigo aproxima-se da perspectiva da antropologia política e urbana. Ao contrário das análises que representam o período de 1945 a 1964 como "populista", e que insistem na falta de "modernidade" ou "cultura 
cívica" dos grupos de migrantes nas cidades brasileiras e na construção da democracia, o artigo revela a forma como se estabeleceu uma gramática da vida pública nas arenas de conflito da política das favelas no Rio de Janeiro (Cefäi et al.; Cefaï, 2001). Além disso, reconhece que o conceito de populismo é incapaz de descrever a dinâmica social do período, por ofuscar as lutas dos trabalhadores e as suas linguagens políticas e por reproduzir um discurso autoritário, numa tradição do pensamento social brasileiro que identificou o "povo" como a alteridade política negativa do Estado e da República (Zaluar, 1985; Paoli; Sader, 1986; Ferreira, 2001; Gomes, 2001; 2002; Duarte; Fontes, 2004; Oliveira, 2018).

\section{Os militares-prefeitos Hildebrando Gois (1946-1947) e Ângelo Mendes de Morais (1947-1951) e a "batalha das favelas"}

Os moradores de favelas buscaram ser reconhecidos como parte da classe trabalhadora na luta por direitos. Na década de 1940, a redemocratização, com o fim do Estado Novo (1937-1945), a criação dos partidos nacionais, a instauração da justiça eleitoral e a urbanização concorreram para a ampliação da concorrência eleitoral e participação dos trabalhadores na política de massa. Diferentes associações, partidos, lideranças engajaram-se no objetivo de representar os "trabalhadores brasileiros" no espaço público, tendo destaque as culturas de esquerda e as lideranças carismáticas de diferentes matizes ideológicos na formação das linguagens políticas. Além disso, o reconhecimento dos sindicatos e direitos sociais dos assalariados urbanos, como definido no Código de Leis Trabalhistas (1943) e incorporado na Constituição de 1946, estabelecia outros parâmetros para a luta dos trabalhadores reivindicarem direitos.

Os trabalhadores moradores nas favelas aproveitaram da ampliação da concorrência política e eleitoral para reivindicar melhorias, arruamentos, escadas, bicas e outras demandas. Através de lideranças com perfis heterogêneos, articulavam os associativismos de moradia e lazer nas favelas, 
faziam uso da patronagem política e de uma gramática de direitos que politizava o espaço urbano. No final da década de 1940 e início de 1950, o legislativo e executivo do Rio de Janeiro receberam inúmeras manifestações para suspender despejos coletivos e reivindicar o "direito de moradia" nas favelas. Essas manifestações contestavam o status ilegal das favelas e articulavam identidades sociopolíticas que se contrapunham à representação dos pobres urbanos como classe perigosa. O Partido Comunista do Brasil (PCB) e o Partido Trabalhista Brasileiro (PTB) destacavam-se na mobilização e representação dos interesses das favelas (Pandolfi; Grynzpan, 2002; Fischer, 2008; Gonçalves, 2013).

O poder público não demorou a oferecer respostas às mobilizações, em tentativas de estabelecer o controle social e oferecer uma solução para o "problema da favela". Em 1947, o prefeito Hidelbrando de Araújo Góes (1946-1947) criou uma instituição para reforçar a assistência social nas favelas: a Fundação Leão XIII. Como parte de um acordo da municipalidade com o cardeal Dom Jaime Barros, a Fundação Leão XIII foi administrada por uma junta que representava a Igreja Católica e o município. O bispo auxiliar Dom José Távora foi o principal patrono da instituição e seu diretor entre 1949 e 1955 (Valla, 1986; Honorato, 2012).

O objetivo da entidade era "prestar ampla assistência social aos moradores dos morros, das favelas e de locais semelhantes na Cidade do Rio de Janeiro", fornecendo "assistência material e moral". A instituição estava autorizada a manter "escolas, ambulatórios, creches, maternidades, cozinhas e vilas populares" (Prefeitura do Distrito Federal, 1947, p. 897). Como é fácil perceber pela legislação, a principal preocupação era a recuperação e o atendimento das "famílias" e "crianças", tendo em vista um projeto civilizacional cristão de assistência aos "pobres". Para tanto, foram construídos e mantidos seis Centros de Ação Social (Barreira do Vasco, São Carlos, Jacarezinho, Morro dos Telégrafos, Salgueiro e Rocinha) e duas Agências Sociais (Praia do Pinto e Cantagalo), onde funcionavam lactários e eram oferecidos ensino religioso e cursos técnicos e profissionais. 
Entre 1947 e 1950, a Fundação Leão XIII, com auxílio de verbas do governo federal e do Instituto de Previdência Social dos Industriários (IAPI), construiu e administrou uma vila operária (um conjunto de casas geminadas na Barreira do Vasco), defendendo uma política de habitação social e urbanização seletiva - parte das favelas e dos favelados deveria ser recuperada como trabalhadores para a sociedade urbana-industrial, a outra parte estava excluída por ser identificada como marginal. Entretanto, o principal mote da entidade era a atuação no campo do serviço social. Pelo programa "A Fundação Leão XIII e seu plano de trabalho", a organização tinha como finalidade

pugnar pela extinção progressiva das favelas, educar o habitante da favela e criar, para ele, um ambiente de sadia moralidade por meio dos seus Centros de Ação Social, célula mater de todo o movimento social popular. Implantados seus Centros no próprio âmago da favela, procura o Serviço Social revolucionar o meio, de forma a suscitar o aparecimento do espírito de responsabilidade familiar e social, de amor ao trabalho e ao Brasil, de compreensão humana e solidariedade cristã (Fundação Leão XIII, 1950, p. 43).

No espírito da doutrina social católica, a fundação tentava proteger a família e estabelecer um associativismo, que era descrito como um "movimento social popular". Num contraponto às esquerdas, principalmente aos comunistas, ela manteve um Serviço Associativo em sua estrutura organizacional. Sob a justificativa de "orientar" os moradores para evitar "agitações que poderiam ser exploradas por empreiteiros da desordem", a igreja almejava interferir nas disputas políticas das favelas e controlar as formas associativas (Valla, 1986; Lima, 1989; Burgos, 2006; Valladares, 2005; Gonçalves, 2013; Oliveira, 2014).

Em 1948, o Departamento Nacional de Gás e Iluminação fechou um acordo com a Fundação Leão XIII com o objetivo de controlar o fornecimento de luz em favelas, através da instalação de um "medidor único" (Departamento Nacional de Gás e Iluminação, 1948, p. 5685). Como entidade organizadora da distribuição de luz, o Serviço Associativo da fundação, juntamente com os Centros de Ação Social e os moradores de 
diferentes localidades, foi responsável pelo atendimento das demandas por instalação de medidores de energia que, dessa forma, transformou o acesso e a distribuição de energia elétrica em um importante recurso associativo e político. Estima-se que a Fundação Leão XIII tenha estado presente em cerca de trinta e três favelas (Valla, 1986; Soares, 2013).

A campanha jornalística a "Batalha do Rio", liderada por Carlos Lacerda, surgiu numa aliança entre liberais e católicos para se contrapor ao que consideravam como a "demagogia" de comunistas e das esquerdas. Num reforço à atuação da Fundação Leão XIII e num apelo à atuação do poder público no controle do espaço urbano, mostrava a favela como um problema do "egoísmo" e do "individualismo" da modernidade. A ação da igreja e a solidariedade cívica dos cidadãos eram exaltadas como meio de recuperar os pobres e "humanizar" as favelas.

O prefeito Ângelo Mendes de Morais (1947-1951) aproveitou o mote da campanha jornalística, de ampla repercussão nos órgãos da imprensa, para operar com a metáfora da "batalha" e sugerir uma rápida intervenção militar para eliminar as favelas no prazo de um ano: o "Plano geral para a solução das favelas". Desde 1940, constituiu-se na prefeitura do Distrito Federal uma comissão, subordinada à Secretaria Geral de Assistência e Saúde, para tratar das favelas. Angelo Mendes de Morais reformou a instituição, construindo uma nova Comissão de Favelas (Prefeitura do Distrito Federal, 1948). A "batalha" lançada por Angelo Mendes de Morais era metafórica e real, sendo a Comissão de Favelas responsável pela execução do plano de guerra.

O plano foi dividido em três fases: na primeira, realizar-se-ia o estudo estatístico da "fase preparatória" para conhecer as favelas; na segunda, far-se-ia uma "apreciação dos 'meios'”, na terceira, a municipalidade desencadearia uma ação final, "o dia D". O documento publicado fala em "Dia D+30", "Dia D+60", num escalonamento progressivo da ação que eliminaria as favelas em um ano. Seguindo um vocabulário e uma lógica de guerra, o plano projetou vários "expurgos", numa interdição da vida nas favelas e na seleção dos moradores através de várias categorias de 
exceção. Segundo o "Plano geral para a solução das favelas", em sua fase final, haveria o "desencadeamento da ação" da seguinte forma:

A) Iniciadas as providências da letra C, no dia D:

a) interdição absoluta da favela nesse dia.

b) encaminhamento dos "expurgados":

1. Amparados pelos institutos de previdência e indústria (Ministério do Trabalho);

2. Entrega à Polícia Civil (vadios, prostitutas, criminosos e exploradores);

3. Fechamento e demolição das "biroscas" (biroscas, botequins cabarés, casas de jogo e de tolerância);

4. Suspensão de pagamento de aluguel por todo e qualquer favelado;

5. Encaminhamento para asilos, institutos, internatos e hospitais dos velhos, crianças, enfermos;

6. Destruição dos casebres abandonados ou desocupados e dos que surjam depois do dia D;

7. Demolição dos que ofereçam perigo, encaminhando-se as famílias para o Albergue e outros destinos;

8. Entrega aos governos estaduais, com transporte e auxílio, aos que desejarem retornar à origem e à lavoura;

9. Encaminhamento dos desempregados que possuam profissão e desejam emprego no Distrito Federal (São Francisco, Siderúrgica e outros);

10. Estrangeiros indesejáveis - Polícia Civil e Ministério do Exterior (Prefeitura do Distrito Federal, 1948, p. 4824-4825).

O plano inseria-se nos parâmetros culturais e políticos da época, que entendiam a favela como um espaço transitório da cidade. Tal como 
afirmado nas legislações urbanísticas após o Código de Obras de 1937, as favelas eram vistas como espaços ilegais que seriam proibidos e destruídos pela fiscalização municipal. A noção de "expurgo" e "depuração" dos moradores tinha forte conotação higienista e racista, sendo um produto social reproduzido em outras ocasiões e nos discursos heterotópicos que tomavam a favela como "problema".

Como parte da retórica da marginalidade social que atravessou as diferentes políticas públicas do período, o "Plano geral para solução das favelas" falava abertamente em um processo de "depuração" dos moradores: a separação do trabalhador que seria direcionado para as indústrias, dos "inadaptados" ao ambiente urbano que retornariam para a "lavoura" e das classes perigosas ("vadios, prostitutas, criminosos e exploradores") para a prisão. Foi nesse contexto que a Fundação Leão XIII e suas diferentes iniciativas para estabelecer o controle social dos territórios das favelas ganharam corpo e legitimidade. O serviço social da municipalidade configurou-se a partir de uma declaração de guerra contra as favelas cariocas e sua inserção na esfera pública após a redemocratização.

A política urbana na retórica das "batalhas das favelas" tinha como pressuposto o controle da ação dos moradores e suas associações, acusadas de serem "comunistas" e "demagógicas". A gramática da guerra acionada por autoridades públicas e imprensa não eliminava as favelas, mas restringia o espaço público e controlava as arenas de conflito articuladas pelos trabalhadores na luta por direitos. A Guerra Fria, o anticomunismo e um urbanismo autoritário ancoravam a restrição da cidadania para as favelas na cultura política carioca.

\section{A Comissão de Favelas e as suas "batalhas" (1951-1954)}

Nos anos 1950, ocorreram tentativas de coordenar e centralizar os órgãos da política pública para as favelas. Tanto o executivo quanto o legislativo municipal ensaiaram projetos que centralizavam numa autarquia as várias funções e práticas desenvolvidas em diferentes segmentos da 
administração que atuavam nas favelas. Os prefeitos João Vital (19511952) e Pedro Alin (1952-1954), nomeados por Getúlio Vargas (19511954), responderam a essa expectativa de racionalização da administração e reformaram a Comissão de Favelas, mantendo o caráter restritivo da cidadania na nova "batalha" para extinguir as favelas.

A partir de 1952, a Comissão de Favelas assumiu um caráter diretivo, e funcionou, com diferentes composições, vinculada ao gabinete do prefeito até a sua extinção em 1956 - quando foi substituída pelo Serviço de Recuperação de Favelas e Habitações Anti-Higiênicas (SERFHA). A Comissão de Favelas funcionava como um conselho e reunia todos os departamentos da prefeitura que atuavam na questão das favelas. Diferenciava-se das comissões anteriores por ter um presidente que assumia, na cena pública, os posicionamentos do governo na solução do "problema das favelas" (Prefeitura do Distrito Federal, 1952, p. 1). Segundo a portaria municipal de janeiro de 1952, o médico Guilherme Romano foi nomeado chefe da referida comissão, com a função de executar o estudo e a coordenação dos diversos serviços de "engenharia sanitária e assistência médica e social" para intervir nas favelas. No exercício de suas funções, ele poderia requerer recursos materiais e verbas ao prefeito do Distrito Federal e também "dirigirse diretamente aos Secretários Gerais e demais autoridades municipais" (Prefeitura do Distrito Federal, 1952).

Esse caráter diretivo da Comissão de Favelas, quase uma secretaria de Estado, era percebido pelas elites políticas e pela imprensa que the atribuíam o nome de "Superintendência Geral de Favelas". Na esfera pública, a metáfora da "batalha" contra as favelas era retomada:

O problema das favelas cariocas - acentuou o Dr. Guilherme Romano - está sendo encarado por mim e pelos meus assessores, de acordo com um programa que esbocei, como uma questão que não se solucionará senão com a ajuda de várias entidades de Previdência e Assistência, dos Estados interessados e, sobretudo, dos órgãos técnicos que mais diretamente entrarão em contato com o problema. Pelo referido esboço, atendendo-se tanto possível ao que já existe estudado e planejado até o momento - iniciaremos a chamada "batalha das favelas" ainda hoje, pondo em execução: 1) medidas de urbanização, 
com um mínimo de higiene e segurança dos seus habitantes que se dediquem ao trabalho e ao sustento de suas famílias; 2) entregar aos respectivos órgãos de Previdência, Assistência etc., os problemas que formos levantando aos respectivos contribuintes e associados das favelas; 3) expurgar elementos indesejáveis, inclusive os exploradores das favelas. Será dado todo apoio aos trabalhadores, dispensando todo o rigor possível, de acordo com a lei, aos elementos que perturbam a vida das famílias ali residentes e da população em geral; 4) garantir água, luz, esgoto, ordem e higiene, dentro das condições de sua vida de trabalhadores favelados; construção de um Parque Proletário para o qual será transferido, progressivamente, a população da primeira favela a ser atacada, provavelmente a de Jacarezinho; 5) adoção de medidas em colaboração com a Chefia de Polícia, visando a que novos barracos não sejam construídos e a que, por consequência, não se criem novos núcleos de favelados (Começa..., 1952, p. 16).

Na reportagem publicada no jornal diário A Noite, o médico destacava o intento de cumprir o desejo do presidente Getúlio Vargas, de "dar aos favelados melhores condições de vida", fazendo uma referência ao plano nacional de extinção de favelas anunciado pela Comissão Nacional de Bem-Estar Social (CNBS). Criada no âmbito do Ministério do Trabalho, a CNBS instituiu uma Subcomissão de Habitação e Favelas e gerou uma expectativa de unificação de recursos públicos federais para aplicação numa política de habitação popular em escala nacional (Subcomissão de Favelas, 1952). Na percepção de Guilherme Romano, o Ministério do Trabalho, através da CNBS, traçaria um "roteiro" para "as atividades da administração pública em todos os seus planos para a solução" do problema das favelas, oferecendo "ao órgão executor que é a Municipalidade, a assistência para o planejamento" (Higiene..., 1952, p. 1).

O programa esboçado pelo médico Guilherme Romano tinha como foco a "urbanização" das favelas. O termo não significava a generalização de bens e serviços para favelas, mas a promoção de uma ideologia urbana e de um projeto de civilidade e de educação para os moradores. Isso implicava uma distinção entre o "trabalhador favelado" e os "elementos indesejáveis". As medidas de urbanização seriam direcionadas às localidades e àqueles "que se dedicassem ao trabalho e ao sustento da família"; nesse mesmo 
viés, falava-se numa seleção para encaminhar as famílias de trabalhadores à Previdência Social e à assistência social (Prefeitura do Distrito Federal, 1952).

Nesse projeto de "urbanização" e "humanização" das favelas, ao mesmo tempo em que havia uma preocupação com a heterogeneidade das favelas, falava-se também numa seletividade para a erradicação da marginalidade social. Tratar o morador de favela como um trabalhador e reconhecer sua inserção no mercado e sua contribuição para os Institutos de Aposentadoria e Pensão, como enfatizava a política de Getúlio Vargas, não implicava apagar as categorias de exceção ligadas à associação das favelas às classes perigosas. Falava-se novamente em "expurgos" que seriam feitos contra os indivíduos que não comprovassem ser trabalhadores e contra os "exploradores de favelas" - o segmento que, vivendo ou não na favela, alugava barracos ou o chão, controlava o acesso a fontes de água ou às "bicas" (torneiras públicas), e outros negócios articulados naqueles espaços.

No intento de promover a reforma social e construir um éthos de trabalhador ordeiro, a Comissão de Favelas promoveu remoções e acordos para construção de habitações populares. Em 1952, foram removidos os moradores da favela Hípica para o conjunto habitacional Dona Castriota, no Horto/Jardim Botânico (Silva, 2005). No mesmo ano, a municipalidade firmou acordo com o Instituto de Previdência e Assistência Social dos Servidores do Estado (IPASE) para a construção de habitações populares "modestas", tendo em vista a "solução da questão das favelas". Dois empreendimentos da política de habitação do IPASE foram negociados para beneficiar os "trabalhadores favelados": a construção de apartamentos no conjunto residencial em Marechal Hermes e a construção de casas em Jacarepaguá, na Rua Dr. Bernardino. Segundo uma reportagem do Correio da Manhã, o diretor do IPASE explicou que

as condições para a aquisição de moradia pelos associados são as mesmas a que tem de satisfazer os demais funcionários (...) assim, deverá o interessado fazer prova da sua condição de favelado, apresentando certidão fornecida pela Fundação Leão XIII, entidade que procedeu ao levantamento das favelas e condições de vida dos seus habitantes (Apartamento..., 1952, p. 4). 
Os critérios de seleção dos servidores na "condição de favelado" seriam bastante restritos, visto que se limitavam àqueles que trabalhavam na administração pública, e contribuíam para o IPASE. Além da inserção no mercado de trabalho regular, havia o controle instituído pela Fundação Leão XIII na certificação das famílias que teriam acesso à "condição de favelado". De acordo com a Instrução no 22 do IPASE, a "situação de favelado" garantia de noventa a trezentos e sessenta pontos aos beneficiários, de acordo com o tempo de moradia na favela, para se qualificar no acesso à política de habitação social. Para comprovar essa "condição de favelado", o beneficiário dependia do cadastro de moradores mantido pela Fundação Leão XIII (Instituto de Previdência e Assistência dos Servidores do Estado, 1952, p. 9535-9584).

Assim, podemos compreender que, apesar de colocar a questão social em evidência, articulando-a ao Ministério do Trabalho, a Comissão de Favelas dirigida por Guilherme Romano também enquadrava sua prática numa "batalha" de cunho moral e social. Identificava na favela um "mal" a ser "expurgado" da cidade, com a respectiva "recuperação" do trabalhador para a sociedade urbano-industrial. Ainda que Guilherme Romano afastasse o horizonte de um plano militar para o "expurgo" das favelas, também dialogava com as categorias de exceção construídas pela ótica da assistência social e pela dimensão jurídico-urbanística que enfatizava a ilegalidade das favelas. Na arena de conflito construída no período, a política de favelas era limitada pelos critérios restritos da cidadania regulada, que identificava o "trabalhador" inserido no mercado formal como portador de direitos e excluía parte significativa dos moradores e migrantes pobres que não comprovassem vínculo de emprego através da carteira de trabalho e contribuição aos Institutos de Previdência Social.

\section{A União dos Trabalhadores Favelados e a "cruzada" contra as favelas (1954-1961)}

A crise do governo de Vargas e a ampliação da mobilização dos trabalhadores foi chave na redefinição da política das favelas. Em 1954, União dos Trabalhadores Favelados (UTF) destacou-se na cena pública 
como movimento social. A associação surgiu no morro do Borel, vinculada à luta para evitar o despejo coletivo pretendido pela empresa Borel Meuron Ltda. A mobilização também tinha o objetivo de reunir outras associações de moradores e recreativas em torno de uma agenda de luta por direitos. Assim, a UTF mobilizou a solidariedade entre lideranças de favelas em localidades distintas, explorou as oportunidades de protesto na política de massa (aproximando-se de sindicatos e partidos de esquerda), e reivindicou o reconhecimento de uma identidade política em oposição ao discurso de classe e raça que associava as favelas às classes perigosas.

"Trabalhador favelado" tinha uma conotação distinta e mais ampla que a política encaminhada pela Comissão de Favelas do governo de Vargas. Na segunda metade da década de 1950, a UTF foi um movimento social que estimulou a fundação e buscou reunir o maior número de associações de moradores em protestos urbanos. Denunciou a atuação de "grileiros" e "exploradores" nas favelas, reivindicou o "direito de moradia" e "melhoramentos urbanos" e questionou a atuação dos órgãos públicos nas favelas, que legitimava as arbitrariedades dos despejos contra os "trabalhadores favelados". Entre as ações da UTF destacou-se a realização de "congressos de favelas", reunindo várias lideranças em torno da defesa de um projeto de lei que tinha por objetivo reconhecer o direito de moradia dos "trabalhadores favelados" para evitar despejos e estabelecer a urbanização em várias localidades. Em 1955, essas lutas repercutiram na Câmara Federal: foi criada uma Comissão Parlamentar de Inquérito (CPI) para investigar os "despejos ilegais" nas favelas. Toda uma gramática política da luta pelo direito de moradia compôs parte do repertório do associativismo urbano da UTF (Lima, 1989; Fischer, 2008; Amoroso, 2012; Gonçalves, 2013; Oliveira, 2014; 2018).

Uma das personalidades de destaque no movimento de trabalhadores favelados era Antoine Magarinos Torres Filho, reconhecido como o "sócio fundador no 1" da UTF e o "advogado das favelas". Ele atuava em proximidade com os comunistas e com o trabalhismo - principalmente após a larga a mobilização getulista com o suicídio de Vargas. Magarinos 
Torres tentou, por mais de uma vez, candidatar-se a cargos políticos no Rio de Janeiro, defendendo a causa das favelas e dos "posseiros", na luta pela reforma urbana e agrária. Em 1958, a UTF foi fechada pela polícia política, acusada de ser uma frente ilegal do PCB, mas, posteriormente, o movimento foi reconstruído a partir da mobilização de outra entidade, a Coligação dos Trabalhadores Favelados (CTF) (Amoroso, 2012; Oliveira; Pandolfi, 2019).

Em reação à mudança de repertório de ação coletiva das favelas, que se organizava de maneira supralocal e reivindicando a ampliação dos direitos dos trabalhadores, o poder público reforçou sua aliança com a Igreja Católica, aproveitando-se da realização do 36ํㅡ Congresso Eucarístico Internacional. O congresso ocorreu no Rio de Janeiro em 1955 e destacou o lugar da doutrina social cristã na Guerra Fria e na transformação da realidade brasileira. No evento, foram lembradas as inúmeras obras da igreja que assistiam a população brasileira onde "faltava" o Estado. Entre as Santas Casas de Misericórdia, os Círculos Operários e as ações voltadas para o indígena e os camponeses no meio rural, figurava a Fundação Leão XIII nas favelas cariocas (Ação..., 1955).

Em sintonia com o Congresso Eucarístico, foi criada a Cruzada São Sebastião. Retomava-se o mote da "batalha" contra as favelas, agora uma "cruzada" para salvar a cidade na comemoração de seu quarto centenário. De acordo com o cardeal Dom Jaime de Barros Câmara, a Cruzada São Sebastião distinguia-se por "um plano de longo prazo - a tentativa de urbanização de todas as favelas do Rio de Janeiro, em 12 anos, tendo como alvo o IV Centenário da cidade, (...) - e um plano emergencial - a urbanização em 4 meses da favela da Praia do Pinto" (Urbanização..., 1955 , p. 6). Estruturada a partir de um estatuto de autoria do cardeal Dom Jaime Câmara, presidente da mesma, a Cruzada São Sebastião tinha como secretário geral o bispo auxiliar do Rio de Janeiro, Dom Hélder Câmara seu principal articulador e "fundador" que vinculou seu nome à memória da entidade (Estatuto..., 1958, p. 8). 
Se a Fundação Leão XIII, criada em 1947, especializava-se na assistência social ao longo da década de 1950, a Cruzada tinha o propósito de atuar na produção da habitação social. Diferente da Fundação Leão XIII, que teve uma breve incursão na construção de uma "vila operária" na Barreira do Vasco, a Cruzada surgia com intento de "urbanizar" a favela Praia do Pinto, com auxílios e subvenções concedidas pelo presidente Café Filho (1954-1955). Instituída como uma associação civil, a Cruzada definia-se como uma campanha para sensibilizar o Estado e a sociedade, tendo "duração limitada" e procurando

para cada Favela a solução mais indicada, salvaguardando os seguintes princípios: a) agir congregando ao máximo as forças disponíveis da iniciativa particular e do Poder Público, acima das divisões político-partidárias e discriminações raciais; b) conjugar medidas de solução direta com providências de ordem geral para que o trabalho empreendido não redunde em agravação do problema das Favelas; c) dar à ação educativa o lugar essencial que lhe cabe no campo educacional, ir à fonte que é a família com a melhor providência em favor dos menores (Correio da Manhã, 1955, p. 8).

A Cruzada São Sebastião funcionou entre 1955 e início dos anos 1960, tentando articular a iniciativa privada e o poder público em uma campanha para "urbanizar" as favelas - categoria usada num sentido histórico específico e que não deve ser reduzido apenas à instalação de infraestrutura urbana. Ao defender a "urbanização" das favelas, Dom Helder Câmara defendia que a maioria dos favelados não era constituída de "marginais", mas de "trabalhadores" que contribuíam com os Institutos de Pensão e Aposentadoria. Segundo Dom José Távora, que presidia a Fundação Leão XIII e defendia a campanha da Cruzada, a premissa para urbanização era o combate ao "horror burguês que se apossa de certas pessoas bem instaladas na vida, que julgam ser as favelas apenas centros de 'malandragem'", e à ideia de que a "solução proposta contra os 'malandros', é a remoção drástica e impiedosa das favelas do centro e da zona sul para a periferia da cidade" (Dom Hélder..., 1955, p. 7-12). No argumento, havia o reconhecimento das campanhas e protestos de trabalhadores favelados na 
esfera pública. Além disso, a dicotomia "trabalhador/malandro" nas favelas e o "horror burguês" à pobreza serviram de mote para Dom Hélder Câmara reivindicar recursos públicos e para concitar as classes médias e empresariais a colaborar com seu projeto. O bispo auxiliar do Rio de Janeiro circulou em reuniões das famílias de classe média e alta, palestrou em associações comerciais e no Jockey Club, assim como realizou diferentes campanhas na imprensa incentivando doações e recursos para solucionar o problema das favelas cariocas.

A "urbanização" ganhava aspectos particulares na visão da Cruzada São Sebastião. De um lado, havia o reconhecimento das particularidades de cada favela, sendo necessário atender as demandas de melhoramento de cada localidade na articulação com o poder público. Por outro lado, urbanizar era "humanizar" as favelas, alterando o modus vivendi da população: combater a "promiscuidade" e difundir os preceitos cristãos era o foco de uma mudança de comportamento que tinha como eixo central a recuperação dos valores da família na sociedade. Como notou Valla, a urbanização "traduzia-se em todo um trabalho de persuasão da população no sentido de levá-la a aceitar e implantar um novo modus vivendi" associado à imagem de trabalhador e cristão (Valla, 1986, p. 72).

Dom Helder também anunciou a criação de uma "colônia" agrícola em Goiás, tentando fixar os moradores do "interior" e apoiar o processo de interiorização do Brasil defendido pelo presidente Juscelino Kubitschek na construção de Brasília. Na mudança da capital federal, a Cruzada São Sebastião reafirmava seu compromisso de eliminar as favelas para as comemorações do IV Centenário do Rio de Janeiro e de apoiar o desenvolvimentismo.

Uma das principais obras da Cruzada São Sebastião foi a construção do conjunto habitacional "Bairro São Sebastião" - 916 apartamentos no bairro do Leblon e distribuídos por dez prédios. Iniciado seu planejamento em 1955 e inaugurado em 20 de janeiro 1957 (dia do santo padroeiro do Rio de Janeiro), o conjunto situava-se numa das áreas mais valorizadas da zona sul carioca e destinava-se à "urbanização" da favela da Praia do 
Pinto, localizada às margens da Lagoa Rodrigo de Freitas. Construído com subsídio do governo federal, essa foi a obra de maior visibilidade da Cruzada São Sebastião, simbolizando o ataque ao "horror burguês" às favelas e a pregação da solidariedade e colaboração entre classes sociais - uma apologia à "paz social e cristã" contra a filosofia do comunismo. Apesar do discurso que enfatizava a integração de classes sociais, o conjunto destinado aos moradores da favela Praia do Pinto foi criticado e estigmatizado, sendo também tratado em diversas situações como um enclave da pobreza na zona sul carioca (Gonçalves, 2013).

A proposta da Cruzada São Sebastião distinguia-se também pela existência de uma ideologia comunitária para evitar a demagogia política e para instrumentalizar o mutirão como meio de conquista de melhorias. Essa visão comunitarista foi apregoada por outra instituição coetânea da Cruzada, o Serviço de Recuperação de Favelas e Habitações Anti-Higiênicas (SERFHA). No documento que criou órgão, apregoava-se que "qualquer programa habitacional, deve conjugar uma larga ação social e educativa, visando obter dos beneficiários um esforço para a manutenção e melhoria de seus lares e uma participação ativa na vida comunitária, por meio do sistema de ajuda mútua" (Prefeitura do Distrito Federal, 1956, p. 1).

No SERFHA, havia a compreensão da favela como um problema geral de "habitações substandard" e "anti-higiênicas" que seria comum em outras cidades e na zona rural brasileira, sendo um problema intimamente ligado à rápida urbanização e ao desenvolvimento urbano-industrial. Isso implicava também uma classificação entre as favelas "condenáveis" e as "recuperáveis". Naquelas vistas como "recuperáveis", o órgão buscava incentivar o mutirão, que era entendido como uma prática social proveniente do meio rural e que poderia ser aperfeiçoada pelo Estado, ajudando a urbanizar as favelas e economizar os recursos escassos do poder público para enfrentar o problema habitacional.

O SERFHA ocupou o lugar da Comissão de Favelas na estrutura municipal de governo. Assim como a instituição que o precedeu, tinha objetivo de congregar as várias políticas públicas que existiam no âmbito 
municipal. Criado em 1956, pelo prefeito Francisco Negrão de Lima (19561958), o SERFHA tinha grande semelhança com o projeto de 1952 que foi organizado pela Comissão Nacional de Bem-Estar Social (CNBS), no Ministério do Trabalho (Almeida, 1953). Na interpretação do "problema das favelas", o SERFHA estava fortemente impregnado da visão constituída na Subcomissão de Habitação e Favelas da CNBS, durante o governo Vargas.

Entre 1956 e 1960, o SERFHA atuou em conjunto com a Fundação Leão XIII e, principalmente, com a Cruzada São Sebastião. Segundo Parisse, o primeiro coordenador do órgão, Reinaldo Mattos Reis, era ligado à Cruzada São Sebastião (Parisse, 1969). Entre 1956 e 1959, o diretor tentou ampliar a assistência social, realizando obras que favoreceram a iniciativa católica. Criou quatro Centros Sociais (Penha, Vila da Cachoeira no Alto da Boa Vista, Vidigal e Baixa do Sapateiro em Manguinhos) que foram entregues, respectivamente, à Cruzada São Sebastião e à Fundação Leão XIII. O relatório do SERFHA de 1959 dava destaque a essas obras assistenciais, construídas pelo poder público e sob os cuidados da igreja (Relatório..., 1959).

O SERFHA também atuou em conjunto com a polícia de vigilância e os órgãos da assistência social católica no sentido de conter o crescimento das favelas. Em 1958, o diretor do SERFHA lançou o que chamou de "Operação Cidade Maravilhosa". Também visando à comemoração do IV Centenário em 1965, a operação buscava deixar o espaço urbano livre das favelas e dos camelôs. Segundo o diretor,

quando o Rio de Janeiro fizer quatrocentos anos, (...) espero ter concluído já essa obra, ocasião em que [se] apresenta o Rio de feições novas, para o público e visitantes. Ou seja, todas as favelas e os camelôs serão transferidos, e os camelôs afastados do centro da cidade. (...) Essa tarefa não será desempenhada apenas pela Prefeitura. Para seu pleno êxito, contarei com o auxílio de Dom Hélder Câmara através da Cruzada São Sebastião (Operação..., 1958, p. 5).

Com modelo bastante similar aos "parques proletários", foi construído em Ramos um assentamento, visando a transferência dos moradores nas remoções no Morro do São Carlos, Catacumba e Santo Antônio. A Igreja 
Católica atuou através de seus organismos, prestando assistência social e apoiando as medidas de reassentamento urbano, com o objetivo de modernizar o espaço urbano e de dar melhores condições de vida e reeducar os favelados.

No final da década de 1950 e início dos anos 1960, a arena de conflito das favelas havia sido alterada em grande medida pelo movimento social da UTF. Ampliava-se a esfera de representação dos trabalhadores favelados, incluindo uma ampla luta por direitos de moradia e melhoramentos urbanos. As iniciativas do poder público na arena do conflito tentaram restringir e controlar o movimento social e seus vínculos com a luta dos trabalhadores pela reforma urbana. A Cruzada São Sebastião e a "Operação Cidade Maravilhosa" recuperavam um tropo da batalha que tinha em vista a extinção das favelas e a afirmação de sua ilegalidade. Todavia, o discurso era mediado por uma ideologia comunitarista que confrontava a solidariedade da UTF com o anticomunismo e que tentava mobilizar os moradores em torno de associações mais próximas do poder público e dos mutirões para construir melhorias. Nos anos 1960, os limites e as possibilidades de conformação de uma arena de conflitos em torno desse comunitarismo terá vários desdobramentos na cultura política carioca e nas mobilizações em favelas.

\section{Considerações finais}

A trajetória da política das favelas, sob signo da retórica das "batalhas" na democracia liberal do pós-guerra, evidenciou o estabelecimento de pressupostos excludentes na cultura política, na construção de uma cidadania precária. Antes do que ficou conhecido como a "era das remoções", nas reformas urbanas impulsionadas pelo governo de Carlos Lacerda e pela ditadura civil-militar, forças políticas heterogêneas, dentro e fora do udenismo, alinhavam-se a um ideal de "desfavelamento" e ajudaram a construir a utopia de extinção das favelas do espaço urbano através do tropo da batalha. 
A gramática das "batalhas das favelas" foi um discurso de ampla circulação na opinião pública e se fixou na cultura política carioca como um padrão para legitimação de ações do poder público em intervenções urbanas. No tropo da guerra, o direito do morador em reivindicar sua cidadania estava limitado pela afirmação da ilegalidade urbana das favelas e pela suspeição da sociabilidade construída pelos trabalhadores, constantemente interpelados pelo estigma de classe e raça que os vincularam à imagem das classes perigosas, e pelo anticomunismo. No contexto da Guerra Fria, o anticomunismo teve papel destacado para interdição dos protestos urbanos e dos associativismos de moradores.

Nas análises de Márcia Leite $(2000 ; 2012)$ e Antônio Luís Machado da Silva (2008) sobre a metáfora da guerra, há um diálogo entre a história social e a sociologia urbana. Eles mostraram como os estigmas das classes perigosas se relacionam com a historicidade da representação da favela e da pobreza urbana, sendo uma das balizas da metáfora da guerra como mediadora da sociabilidade violenta e das políticas neoliberais. No artigo, evidenciamos que o tropo da guerra se inseriu na longa duração da história da política urbana, tendo uma inflexão na democracia liberal do pós-guerra e alterando suas conotações, a depender das relações de força em arenas de conflito específicas.

Samuel Silva Rodrigues de Oliveira é Doutor em História e professor do Programa de PósGraduação em Relações Étnico-Raciais e do Centro Federal de Educação Tecnológica Celso Suckow da Fonseca (PPRER-CEFET-RJ).

$\triangle$ samu_oliveira@yahoo.com.br 


\section{Referências}

1. AMOROSO, Mauro. Caminhos do lembrar: a construção e os usos políticos da memória no Morro do Borel. 2012. 265f. Tese (Doutorado em História, Política e Bens Culturais) - Centro de Pesquisa e Documentação de História Contemporânea do Brasil, Rio de Janeiro, 2012.

2. BURGOS, Marcelo B. Dos parques proletários ao Favela-Bairro: as políticas públicas nas favelas do Rio de Janeiro. In: ALVITO, Marcos; ZALUAR, Alba (Org.). Um século de favela. Rio de Janeiro: FGV, 2006. p. 25-60.

3. CAMPOS, Andrelino. Do quilombo à favela - a produção do "espaço criminalizado" no Rio de Janeiro. Rio de Janeiro: Bertrand Brasil, 2005.

4. CEFAÏ, Daniel (Org.). Cultures Politiques. Paris: PUF, 2001.

5. CEFAÏ, Daniel; MELLO, Marco Antônio S.; VEIGA, Felipe B.; MOTA, Fábio. Introdução. Arenas públicas: por uma etnografia da vida associativa. In: CEFAÏ, Daniel et al. (Org.). Arenas Públicas - Por uma etnografia da vida associativa. Niterói: EdUff, 2011. p. 9-63.

6. DUARTE, Adriano; FONTES, Paulo. O Populismo visto da periferia: adhemarismo e janismo nos bairros da Mocca e São Miguel Paulista (1947-1953). Cadernos Arquivo Edgard Leuenroch, v. 11, n. 20/21, p. 87-119, 2004.

7. FERREIRA, Jorge. O Populismo e sua história: debate e crítica. Rio de Janeiro: Civilização Brasileira, 2001.

8. FERREIRA, Marieta de M. (Org.). Rio de Janeiro: uma cidade na história. Rio de Janeiro: FGV, 2000.

9. FISCHER, Brodwyn. A poverty rights: citizenship and inequality in TwentiethCentury Rio de Janeiro. Stanford: Stanford University Press, 2008.

10. FISCHER, Brodwyn. Quase pretos de tão pobres? Race and social discrimination in Rio de Janeiro's Twentieth-century criminal courts. Latin American Research, v. 39, n. 1, p. 31-59, 2004. http://dx.doi.org/10.1353/lar.2004.0008

11. FREIRE, Letícia de L.; GONÇALVES, Rafael S.; SIMÕES, Soraya S. Uma cruzada do século XX: iniciativas católicas no campo das políticas habitacionais na França e no Brasil. Revista Antropológica, n. 29, p. 201-233, 2010.

12. GOMES, Angela de C. O populismo e as Ciências Sociais no Brasil. In: FERREIRA, Jorge (Org.). O Populismo e sua história: debate e crítica. Rio de Janeiro: Civilização Brasileira, 2001. p. 17-59.

13. GOMES, Angela de C. Reflexões em torno de populismo e trabalhismo. Varia História, n. 28, p. 55-68, 2002.

14. GONÇALVES, Rafael S. Favelas do Rio de Janeiro: história e direito. Rio de Janeiro: Puc-Rio/Pallas, 2013.

15. HONORATO, Cezar. O Assistente Social e as favelas (1945-1964). In: MELLO, Marco Antônio da S. et al. Favelas Cariocas: ontem e hoje. Rio de Janeiro: Garamond, 2012. p. 141-169. 
16. LEEDS, Anthony; LEEDS, Elizabeth. A sociologia do Brasil urbano. Rio de Janeiro: Zahar, 1978.

17. LEITE, Márcia da S. P. Da "metáfora da guerra" ao projeto de pacificação: favelas e política de segurança no Rio de Janeiro. Revista Brasileira de Segurança Pública, v. 6, n. 2, p. 374-389, 2012.

18. LEITE, Márcia da S. P. Entre o individualismo e a solidariedade: dilemas da política e da cidadania do Rio de Janeiro. Revista Brasileira de Ciências Sociais, v. 15, n. 44, p. 73-90, 2000. https://doi.org/10.1590/S0102-69092000000300004

19. LIMA, Nisia T. O movimento de favelas no Rio de Janeiro: políticas do Estado e lutas sociais (1954-1973). 1989. 233f. Dissertação (Mestrado em Ciência Política) - Instituto Universitário de Pesquisa do Rio de Janeiro, Rio de Janeiro, 1989.

20. MACHADO DA SILVA, Luiz Antonio. A continuidade do "Problema da favela". In: OLIVEIRA, Lúcia L. (org.). Cidade: história e desafios. Rio de Janeiro: FGV, 2002. p. 221-237.

21. MACHADO DA SILVA, Luiz Antonio (Org.). Vida sob cerco - violência e rotina nas favelas do Rio de Janeiro. Rio de Janeiro: Nova Fronteira, 2008.

22. MOTTA, Marly S. da; FREIRE, Américo; SARMENTO, Carlos Eduardo (Org.). A política carioca em quatro tempos. Rio de Janeiro: FGV Editora, 2004.

23. OLIVEIRA, Samuel S. R. de. Os trabalhadores favelados: identificação das favelas e movimentos sociais no Rio de Janeiro e Belo Horizonte. 2014. Tese (Doutorado em História, Políticas e Bens Culturais) - Centro de Pesquisa e Documentação de História Contemporânea do Brasil, Rio de Janeiro, 2014.

24. OLIVEIRA, Samuel S. R. de. Associativismo de trabalhadores favelados no Rio de Janeiro e em Belo Horizonte (1954-1964). Estudos Históricos, v. 31, n. 65, p. 349-368, 2018.

25. OlIVEIRA, Samuel S. R. de \& PANDOLFI, Dulce C. Dr. Magarinos Torres Filho: a formação social nas classes médias e a luta das esquerdas no Rio de Janeiro (1940-1950). Revista do Arquivo Geral da Cidade do Rio de Janeiro, n.16, p.205-231, 2019.

26. PANDOLFI, Dulce C.; GRYNSZPAN, Mário. Poder público e favela: uma relação delicada. In: OLIVEIRA, Lúcia L. (Org.). Repensando a cidade: história e desafios. Rio de Janeiro: FGV, 2002. p. 238-255.

27. PAOLI, Maria C.; SADER, Eder. Sobre classes populares no pensamento social brasileiro: notas de leitura sobre acontecimentos recentes. In: CARDOSO, Ruth (Org.). A aventura antropológica: teoria e pesquisa. São Paulo: Paz e Terra, 1986. p. 39-68.

28. PARISSE, Luciano. Favelas do Rio de Janeiro: evolução e sentido. Rio de Janeiro: Cenpha, 1969.

29. SILVA, Maria Lais P. da. Favelas Cariocas (1930-1964). Rio de Janeiro: Contraponto, 2005. 
30. VALLA, Victor. Educação e favela: políticas para as favelas do Rio de Janeiro, 1940-1985. Petrópolis: Vozes, 1986.

31. VALLADARES, Lícia do P. A invenção da favela: do mito de origem à favela. com. Rio de Janeiro: FGV, 2005.

32. ZALUAR, Alba. A máquina e a revolta. As organizações populares e o significado da pobreza. São Paulo: Brasiliense, 1985.

\section{Fontes}

1. AÇÃO social inspirada no pensamento católico. Tribuna da Imprensa, Rio de Janeiro, p. 4, 16 set. 1955.

2. ALMEIDA, Rômulo. Relatório da Subcomissão de Habitação e Favelas ao presidente da CNBS. Anexo I - Projeto de Lei, 23/12/1953. Centro de pesquisa e documentação de história contemporânea do Brasil. Arq. GVc1952.12.23. Rio de Janeiro: Arquivo Getúlio Vargas.

3. APARTAMENTO para os Funcionários Favelados. Correio da Manhã, Rio de Janeiro, Caderno 1, p. 4, 26 abr. 1952.

4. COMEÇA hoje a Batalha das Favelas. A Noite, Rio de Janeiro, p. 16, 3 mar. 1952.

5. DEPARTAMENTO NACIONAL DE ILUMINAÇÃO E GÁS. Portaria no 1, de 6 de abril de 1948. Diário Oficial da União, p. 5685, 9 abr. 1948.

6. DOM HÉLDER: vamos humanizar as favelas. O Cruzeiro, p. 7-12, 12 nov. 1955.

7. ESTATUTO da Cruzada São Sebastião. Correio da Manhã, Rio de Janeiro, Caderno 2, p. 8, 26 jan. 1958.

8. FUNDAÇÃO LEÃO XIII. Como trabalha a Fundação Leão XIII. Rio de Janeiro: Fundação Leão XIII, 1950.

9. HIGIENE e segurança aos habitantes das favelas. A Noite, Rio de Janeiro, p. 1, 4 mar. 1952.

10. INSTITUTO DE PREVIDÊNCIA E ASSISTÊNCIA DOS SERVIDORES DO ESTADO. Instrução no 22, 27/05/1952. Diário Oficial da União, p. 9583-9584, 10 jun. 1952.

11. OPERAÇÃO Cidade Maravilhosa para acabar com favelas e camelôs. Correio da Manhã, p. 5, 5 dez. 1958.

12. PREFEITURA DO DISTRITO FEDERAL. Decreto $\mathrm{n}$ - 13.304, de 28 de agosto de 1956. Diário Oficial da União, Rio de Janeiro, p. 1, 29 ago. 1956.

13. PREFEITURA DO DISTRITO FEDERAL. Decreto $n$ ㅇ 8.797, de 8 de fevereiro de 1947. Diário Oficial da União, p. 897, 11 fev. 1947.

14. PREFEITURA DO DISTRITO FEDERAL. Portaria no 2.148 , de 3 de julho de 1948. Diário Oficial da União, Rio de Janeiro, p. 6976, 9 jul. 1948. 
15. PREFEITURA DO DISTRITO FEDERAL. Portaria no 59, de 23 de fevereiro de 1952. Diário Oficial da União, p. 1, 25 fev. 1952.

16. PREFEITURA DO DISTRITO FEDERAL. Problema das Favelas do Distrito Federal. Diário Oficial da União, p. 4824-4825, 15 jul. 1948.

17. RELATÓRIO do SERFHA está muito distante da realidade. Correio da Manhã, Rio de Janeiro, p. 3, 7 fev. 1959.

18. SUBCOMISSÃO DE FAVELAS. Semana das favelas: favelas. Rio de Janeiro: Comissão Nacional de Bem-Estar Social, 1952.

19. URBANIZAÇÃO das favelas: "nobre como um congresso". Tribuna da Imprensa, Rio de Janeiro, p. 2, 8 nov. 1955. 